\title{
The Best Recommendation Plan to Reduce Foley's Catheter Associated Urinary Tract Infection in Elderly Patients under Home Health Care Services
}

\author{
Hanadi Khamis Al Hamad ${ }^{1,2}$, Essa Al Sulaiti ${ }^{1,2}$, Navas Nadukkandiyil ${ }^{2,3^{*}}$ and Maryam Al Obaidely ${ }^{1}$ \\ ${ }^{1}$ Consultant and Head of Geriatric and Long-term Department, Rumailah Hospital, Hamad Medical Corporation, Doha, Qatar \\ ${ }^{2}$ Qatar Weil Cornell Medical College, Doha, Qatar \\ ${ }^{3}$ Geriatric and Long-term Department, Rumailah Hospital, Hamad Medical Corporation, Doha
}

\begin{abstract}
Objective:To develop and implement an innovative change, in the form of a physical reminder sticker protocol, to mitigate the high incidence of CAUTI in the elderly home care patient population at GLTD.

Methods: A comprehensive literature review was conducted that served to provide a robust evidence base to add assure the implementation programme was grounded in an evidence-based approach. Said literature review also added to steps identified for a facility-wide change implementation. Change management strategies were identified herein. A comprehensive implementation plan, developed in accord with the IHI Model for Improvement was presented.

Evaluation: A variety of evaluation strategies and methodologies were identified to assess baseline data, interim data, and data results of a pilot implementation, short-term post-implementation results, and long-term postimplementation strategies.

Discussion: Implications for the organisation and clinical setting were discussed. Recommendations for a robust Phase 2 were presented. Project strengths and weaknesses were discussed.

Results: There were a total of 80 patients with catheter under HHCS in the beginning of the project. In the first three months on implementing the CAUTI program there was a significant decreases in the number of patients, from 80 it dropped to 60 a decrease of $25 \%$. The second phase saw a sharp decrease; the catheter was removed from 60 $\%$ of the patients. It was 10 percentage more than the anticipated by $50 \%$ by the end of March 2015 .
\end{abstract}

Keywords: Catheter associated urinary tract infection (CAUTI); Home health care (hhcs); Geriatric and long term care department (GLTD); Institute of health care improvement (IHI); Urinary tract infection (UTI) in elderly

Abbreviations: CAUTI: Catheter Associated Urinary Tract Infection; GLTD: Geriatric and Long Term Care Department; HHCS: Home Health Care Services; IHI: Institute of Health Care Improvement; CDC: Centre for Diseases Control; UTI: Urinary Tract Infection; HAI: Health Care Acquired Infection; JCI: Joint Commission International; APIC: The Association of Professionals in Infection Control; SWOT: Strength, Weakness, Opportunities and Threats; NHSN: National Health Care Safety Network

\section{Introduction}

According to Nicolle, catheter acquired urinary tract infections (CAUTI) are considered among the most common infections attributed to those acquired due to the delivery of healthcare itself. The Centers for Disease Control (CDC, 2015) report CAUTI share the same statistics as pneumonia in their relation to healthcare acquired infections (HAI). The CDC (2015) continues to report that $99.99 \%$ of UTIs are related to urinary tract catheterisation. In fact, upwards of $70-80 \%$ of said CAUTI are associated with indwelling urethral catheters, reported to be the most common amongst all indwelling medical devise. Ultimately, the Institute for Healthcare Improvement [1] reports that the risk of CAUTI associated with all catheter placement ranges from 3-7 \%. The CDC (2015) also reports that CAUTI are responsible for upward of 13,000 deaths on an annual basis. Whilst HAI cost the NHS an estimated $£ 1$ bn, the inpatient financial burden to the NHS attributable to CAUTI averages $£ 123.89$, or $£ 2,295$ per patient.
Nicolle, differentiates between short- and long-term indwelling urinary catheters, highlighting those remaining in situ in excess of 30 days, or long-term, are typically the most common catheter challenge for healthcare. Whilst catheter associated infections are asymptomatic, Nicolle states the term CAUTI specifically refers to those infections that manifest with symptomatic challenges associated with infection. In fact, Jacobsen [2] highlight two of the bacteria most commonly associated with CAUTI are Escherichia coli and Proteus mirabilis. In addition to the inherent difficulties and expense associated with treating HAI, the CDC (2105) reports that once acquired, CAUTI can foster complications including, but not limited to: cystitis, gramnegative bacteria, septic shock, septic arthritis, endocarditis, vertebral osteomyelitis, pyelonephritis, and/or meningitis. Additionally, in men, CAUTI can lead to orchitis, prostatitis, and epididymitis [3].

\section{Problem statement}

The literature has confirmed that there is a direct link between

*Corresponding author: Navas Nadukkandiyil, Specialist in Internal Medicine Hamad Medical Corporation, Geriatrics, Doha, Qatar, Tel: +97433782463; Fax: 0097444398111; E-mail: drnavasnk30@gmail.com

Received February 06, 2016; Accepted May 30, 2016; Published June 06, 2016

Citation: Al Hamad HK, Al Sulaiti E, Nadukkandiyil N, Al Obaidely M (2016) The Best Recommendation Plan to Reduce Foley's Catheter Associated Urinary Tract Infection in Elderly Patients under Home Health Care Services. Aging Sci 4: 152 doi: 10.4172/2329-8847.1000152

Copyright: (c) 2016 Al Hamad HK, et al. This is an open-access article distributed under the terms of the Creative Commons Attribution License, which permits unrestricted use, distribution, and reproduction in any medium, provided the original author and source are credited. 
the inappropriate use of indwelling urinary catheters and the potential for the patient suffering urinary tract health complications [4,5]. Therefore, the IHI (2014) has identified CAUTI as the HAI to receive the highest priority for intervention programmes due to its relative ease of prevention through the application of accepted evidence-based prevention guidelines.

\section{Organizational context}

The state Geriatrics and Long-Term Department (GLTD) where the author is employed is a sponsored organisation accredited by the Joint Commission International (JCI) since 2008. It is responsible for the care of elderly patients from early diagnosis, treatment and followup support. The GLTD is also responsible for the care of patients aged over 14 who have been diagnosed with long-term medical and social issues. Concerning the elderly, the GLTD mission is to promote and maintain quality standards of geriatric and care for the elderly population of the state and to promote continuing research in the geriatric departments. Additionally, the department also trains resident physicians, nurses, and medical physicians in the most efficient manner to ensure they provide the highest level of clinical care for patients. As the current implementation plan is an improvement plan targeting GLTD through a facility-wide strategic approach, all staff will be affected by the change.

\section{Rationale}

Unlike surveillance interventions, which this student researcher believes has its place; this project involves a reminder-based intervention in the form of a CAUTI sticker project. Similar to that demonstrated as effective by Bruminhent [6], that builds on the evidence by providing an appropriate visual feedback that allows nurses to intervene to ensure that catheter removal times are adhered to for patients, which will therefore reduce the potential for patient harm. Bruminhent [6] results evidenced a significant reduction in in CAUTI whilst increasing the numbers of patients remaining catheterised due to appropriate medical need.

The proposed project involves the introduction of a CAUTI sticker system, presented in Table 2 below, which will serve to provide visual feedback [7], which will remind physicians and nurses of the dates of Foley's Catheter insertion. The reason for the using of the framework, which suggested that, any healthcare intervention is likely to have an impact of one of three main areas of the organization that includes structure, processes and outcomes.

\section{Aims and Objectives}

\section{Aim}

The primary aim of the project is to reduce the delays in the removal of Foley's Catheters in elderly patients through the introduction of a robust CAUTI sticker intervention.

\section{Objectives}

Associated objectives for implementation are as follows:

$\diamond \quad$ That GLTD physicians and nurses will have received education and training about the proper implementation of CAUTI Sticker by 15 October 2014

$\diamond \quad$ That a CAUTI sticker will be placed in the medical records of all patients with Foley's Catheter by 1 November 2014

$\diamond$ That HHCS staff will be $100 \%$ complaint with the CAUTI sticker protocol by 1 of December 2014

$\diamond$ By 31 March 2015 Foley Catheter will be removed from 50\% patients under HHCS.

$\checkmark \quad$ By the end of December 2015 the number of CAUTI cases will be reduced to $30 \%$.

\section{Literature Review}

Woolf asserts the literature review is a mechanism to "provide an efficient scientific technique to identify and summarize evidence on the effectiveness of interventions and to allow the generalizability and consistency of research findings to be assessed and data inconsistencies to be explored." This is achieved through the identification, critical assessment, unbiased summation, and synthesis of evidence. Therefore, based upon the goals and objectives of the current project, a comprehensive literature review is consistent with the implementation needs, particularly as it relates to providing evidence based approach to staff education. It is also believed a review of nurse-led intervention programmes to reduce CAUTI amongst the elderly in a community home care setting will allow for greater integration of quality improvement efforts throughout the change process by investigating successful approaches and employing successful strategies.

\section{Inclusion and exclusion criteria}

Given the myriad of evidence existing related to urinary tract infections, and specifically, CAUTI, inclusion and exclusion criteria were developed to retain as focused an approach as possible. For purposes of this literature review, it was required that all evidence be originally published in English to avoid any potential miscommunication or translation errors. It was also required that all articles be published within the eight year boundary for medical obsolescence, unless otherwise excluded evidence would provide relevant information despite its dated nature. Should this be the case, said evidence would be commented upon limited by methodological approach on its selection of evidence; in addition to traditional quantitative and qualitative evidence, guidelines and narrative reports were also included.

\section{Inpatient interventions for CAUTI}

Meddings [8] conducted a systematic review and meta-analysis to

\begin{tabular}{|c|c|}
\hline Strengths & Weakness \\
\hline $\begin{array}{l}\text { - High number of quality } \\
\text { human resources } \\
\text { - Sufficient equipment and } \\
\text { facilities in place } \\
\text { - Adequate supply of } \\
\text { trainer resources }\end{array}$ & $\begin{array}{l}\text { - Lack of knowledge regarding } \\
\text { CAUTI and its impact on patients } \\
\text { - Physician led process interventions } \\
\text { currently in place } \\
\text { - Delays in current catheter removal } \\
\text { procedures }\end{array}$ \\
\hline Opportunities & Threats \\
\hline $\begin{array}{ll}\text { - } & \text { Improve HR skills and } \\
\text { competencies } \\
\text { - Compliance with } \\
\text { standard s and } \\
\text { guidelines } \\
\text { - Enhance quality of } \\
\text { elderly patient care } \\
\text { - } \\
\text { Reduce levels of CAUTI }\end{array}$ & $\begin{array}{l}\text { - Lack of compliance the protocols } \\
\text { - } \quad \text { Lack of understanding of } \\
\text { intervention protocol } \\
\text { - Failure to implement intervention } \\
\text { procedure } \\
\text { - No reduction in level of CAUTI rates } \\
\text { in elderly patients }\end{array}$ \\
\hline
\end{tabular}

Table 1: HHCS SWOT analysis .

\begin{tabular}{|c|c|}
\hline $\begin{array}{c}\text { Accelerating our best care journey in } \\
\text { decreasing CAUTI }\end{array}$ & Patient details \\
\hline Date of Catheter insertion & \\
\hline Indication of Foley's catheter & \\
\hline Date of Catheter removal & \\
\hline
\end{tabular}

Table 2: CAUTI Sticker care bundle. 
investigate the use of reminder systems to reduce catheter-associated urinary tract infections and urinary catheter use in hospitalised patients. Based upon 14 trials, composite results and practice implications highlight that when reminder and stop order protocols are integrated into the hospital setting, incidence of CAUTI was reduced $52 \%$, with a 2.61 day reduction in mean catheterisation time patient [8]. Whilst results are suggestive of effective in-hospital interventions, the systemic review suffered from a number of methodological challenges. For example, articles retrieved contained mixed variables and outcome measures making comparative analysis difficult. Similarly, patient condition including weight, febrile or not, age, gender, post-surgical or not, ICU or not, presence of co-morbid illnesses, admitting diagnoses, and so forth, were uncontrolled variables. Additionally, data collection duration varied, as did follow- up time, interventions, and definition of how to define patient days. Thus, Meddings [8] pooled evidence does not insure reliable and valid result, however, evidence does strongly support acceptance of results as indicative of a trend rather than generalising.

\section{Methodology}

According to MacPhee [9], innovations introduced into the healthcare setting that improve the quality of patient care can be leveraged by effective change management strategies. Meddings [8] stresses that implementing changes designed to reduce incidence of CAUTI by incorporating reminder programmes and intervention bundles into practice require a change of habits. Given the implementation plan contained in this project will result in an organisational change in processes and procedures, this chapter will present a breakdown of change management, barriers to change, change management techniques that will be employed. Implementing a comprehensive programme to effectively manage and reduce incidence of CAUTI will affect the entire organisation; therefore, prior to discussing change and change management techniques, the following organisational background is provided.

\section{Organizational review}

The typical patient load averages 360 inpatients admitted to various state facilities, approximately 150 outpatients but facility based visits per week, and provides home and emergency visits to approximately 1,000 patients cared for under the Home Health Care Services (HHCS) as and when these are required.

\section{Organizational challenges to overcome}

As evidenced throughout this project narrative, the need to effectively manage and reduce incidence of CAUTI is one of the most important issues related to reducing HAI .Whilst there are a number of guidelines to this end [10], and a variety of individual strategies targeting the achievement of this end including reminders [11], and education [12,13], when a strategic comprehensive facilitywide implementation was utilised, results were more effective at the management of CAUTI prevention programmes. However, guidelines fail to address the change management strategy required for a facilitywide implementation. Additionally, implementation models were not incorporated.

\section{IHI model}

As the need to implement an effective intervention programme to reduce and prevent incidence of CAUTI in the elderly population in home care in this student researcher's organisation that will result in a permanent change, the IHI Model will be utilised as the strategic implementation template. Although Shaffer and Thomson emphasis that permanent change requires a long-term strategy, the IHI Model has been identified as an effective process to implement change at an accelerated pace that results in permanent change [14]. Additionally, as the IHI Model [14] has an established history of success within the NHS as the accelerated change model of choice, it is believed that incorporating said model into the GLTD organisational dynamic is appropriate.

\section{Advantages of Change}

The primary aim of the change is to reduce the delays in the removal of Foley's Catheters in elderly patients through the introduction of a robust CAUTI sticker intervention and thus provide an effective management programme to reduce incidence of CAUTI in the home care setting. The resulting advantages would be a measurable impact on the elderly population, in-house staff, and the NHS in general. For example, incidence of, or risk of, CAUTI is more likely to be identified earlier and thus be effectively managed with less disruption and risk of complication to the patient. Staff will have an effective visual reminder system to prevent lapses in patient care. And, less financial burden on the NHS will be incurred by required hospitalisation and treatment of said HAI. All of the advantages of the change will be consistent with guidelines issued on the effective management of catheterised patients.

\section{Disadvantages of Change}

Disadvantages to the change in relation to GLTD staff include resistance to change; a challenge that affects all organisations within the NHS seeking to implement a change despite how positive the change will be for an organisation (NHS Institute for Innovation and Improvement, 2008). The implementation plan that follows strives to incorporate steps that will reduce and/or eliminate said resistance to change. Although there is the additional disadvantage of minimal printing costs involved in the sticker-based reminder system, it is believed a financial analysis will indicate an actual cost savings in required healthcare practitioner time required for patient care when said patient presents with Foley catheter challenges.

\section{SWOT Analysis}

A SWOT analysis (alternatively SWOT matrix) is a structured planning method used to evaluate the strengths, weaknesses, opportunities and threats involved in a project or in a business venture. Given the advantages and disadvantages identified above, a comprehensive SWOT analysis was performed. This is consistent with recommendations by MacPhee [9] who states prior to the development and implementation of a major change, a comprehensive SWOT analysis is appropriate. It should be noted, however, that although a SWOT analysis is not considered appropriate for all healthcare related implementations when stakeholder management is a priority (van Wijngaarden et al., 2012), said analysis is deemed appropriate for consideration herein.

\section{Threats and Challenges}

To assess the potential threat to the successful implementation of the CAUTI sticker process it is first important to identify the strengths and weakness of the current systems and the opportunities for improvement that exist. Therefore, the following SWOT analysis is presented in Table 1.

The SWOT analysis revealed the potential strengths and weaknesses 
of the CAUTI project in HHCS and helped in implementing the change plan. Lack of cognizance of HHCS staff regarding CAUTI and its impact on patients- which was identified to be a major weakness, needed to be tackled in the first phase. In order to collect the baseline data a questionnaire was prepared and distributed among the HHCS staff. Based on the findings, intensive training sessions were started to all staff including physicians, nurses and infection control practitioners about the proper intervention and removal of CAUTI, possible complications and time limit.

\section{Action plan}

An integral part of this project as investigator is to ensure compliance with established objectives and protocols in a manner that leads to improved quality of care for elderly patients. As project leader, the initial task will be to select an appropriate team to assist with the implementation of the proposed CAUTI sticker intervention. Said team will be comprised of members consistent with those suggested by the IHI Model for Improvement [14]. As a lead, this change agent will also be responsible in ensuring that full training and education regarding both reminder sticker processes and current guidelines for the elimination of CAUTI [15], is performed. Furthermore, this prime investigator will also be held responsible for the timely implementation of each stage of the project and in ensuring that systems are in place that provides me with the required feedback to positively evaluate the outcomes of the project and be able to rapidly address any issues that may arise.

\section{Evaluation}

Using the IHI Model for Improvement [14], as the implementation model, the Centre for Disease Control and Prevention [3], offer a comprehensive, iterative evaluation model. Steps of the CDC model include determining stakeholders, identifying the strategy for evaluation, designing the appropriate evaluation plan and an effective action plan to carry our said evaluation, identifying requisite outcome measures, and finally collecting and analysing said data. Therefore, the remainder of these chapter present plans for both short- and long-term evaluations incorporating steps out line here.

Donaldson [16], caution that it is important to identify potential areas of bias in evaluations from all parties queried. For example, responses might vary from participant to participant strictly based upon evaluation anxiety, false reporting, dissatisfaction with the change, hidden agendas from those seeking to derail the implementation, stalling, avoiding or refusing to respond, or lack of information [16].

\section{Proposed methods of evaluation for short-term objectives}

In order to effectively evaluate the effectiveness of short-term objectives, one of the pivotal assessment tools will be a quantitative survey on knowledge, clinical experience, and clinical processes and procedures engaging all healthcare practitioners within the organisation. This is consistent with the use of baseline information from which to identify positive knowledge-based outcomes. Therefore, based upon the evaluation template offered by Weiss, short-term objectives including staff education and the pilot programme will be evaluated per the following action plan. It should be noted that the action plan(s) below are only representative of the detailed level of evaluations suggested for this implementation; a more comprehensive series of evaluations would is recommended to gather evidence to the level of depth this researcher believes is commensurate with the current implementation project. It should further be noted that the following short term and long term action plans in Tables 3 and 4 is considered as supplemental data to the Work Breakdown Structure that is based solely upon the IHI Model [14].

Long term methods for evaluation incorporate many of the same evaluation strategies and approaches identified for short-term evaluations, however, there are additional evaluation questions included in the long term evaluation plan in Table 4 that focus specifically on effectiveness of the project itself to goals and to consequential changes resulting in SWOT criteria following implementation.

\section{Result}

The following graph shows the number Foleys catheter removed during the pre-intervention and post-intervention periods.

There were a total of 80 patients with catheter under HHCS in the beginning of the project. In the first three months on implementing the CAUTI program there was a significant decreases in the number of patients, from 80 it dropped to 60 a decrease of $25 \%$. The second phase saw a sharp decrease; the catheter was removed from $60 \%$ of the patients. It was 10 percentages more than the anticipated by $50 \%$ by the end of March 2015 (Figure 1).

Based on the research conducted for this project, and the projected $50 \%$ reduction in incidence of CAUTI, it is believed that implementing a Phase 2 of the project in the near future that incorporates a virtual reminder system [8] will further reduce incidence of CAUTI within the GLTD organisation. As highlighted in the literature, the combination of a physical and virtual reminder system reduced incidence of CAUTI more than a physical reminder system alone. The virtual reminder system, however, will require significant funding be sourced for programmers. However, only minimal additional training would be required for personnel, as the virtual reminder would be an adjunct to the physical. It is projected that Phase 2 would consist of a simple alert that would pop up when the patient's chart was electronically accessed at scheduled intervals consistent with patient visits. At such time as the virtual reminder alerted the healthcare professional, any acknowledgment of said virtual reminder

\section{FORCES FOR CHANGE FORECAST AGAINST CHANGE}

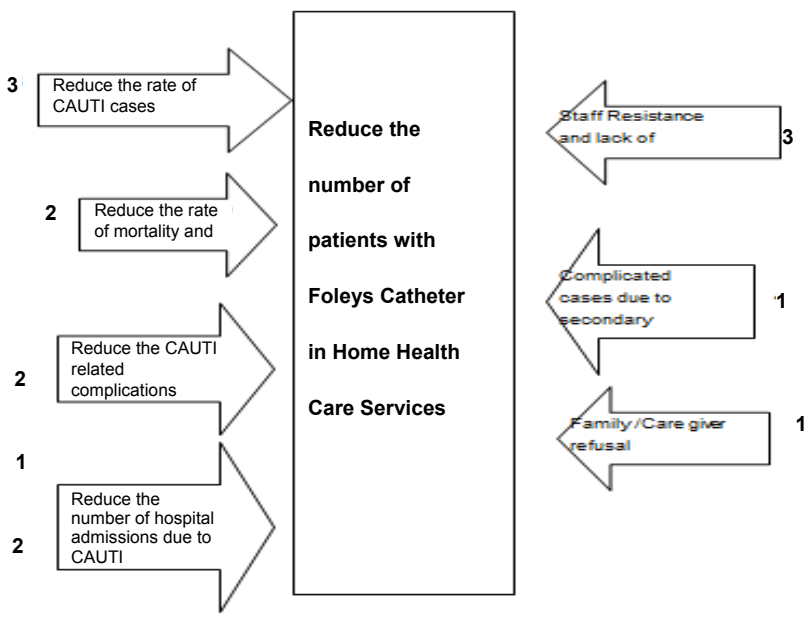

Total Score For

Total Score Against

\begin{tabular}{|l|l|}
\hline 9 & 5 \\
\hline
\end{tabular}

Figure 1: Force field analysis. 


\begin{tabular}{|c|c|c|c|c|c|c|c|}
\hline $\begin{array}{l}\text { Evaluation } \\
\text { Question }\end{array}$ & Indicators & Source of information & Individuals & Data Collected & Method & Data Analysis & $\begin{array}{l}\text { Time Frame for } \\
\text { Reporting }\end{array}$ \\
\hline $\begin{array}{c}\text { Is the project } \\
\text { team effective at } \\
\text { carrying out their } \\
\text { mission }\end{array}$ & $\begin{array}{l}\text { Actual to work } \\
\text { breakdown plan } \\
\text { compliance }\end{array}$ & $\begin{array}{l}\text { Meeting attendance, } \\
\text { work completed per work } \\
\text { breakdown structure }\end{array}$ & Team & $\begin{array}{l}\text { Name, completion, dates } \\
\text {,project documentation }\end{array}$ & Data review & $\begin{array}{l}\text { Descriptive } \\
\text { statistics }\end{array}$ & Weekly \\
\hline $\begin{array}{l}\text { Is educational } \\
\text { training effective }\end{array}$ & $\begin{array}{l}\text { Increase in } \\
\text { practitioner } \\
\text { Knowledge }\end{array}$ & $\begin{array}{l}\text { Results of base line } \\
\text { pre-,and post-education } \\
\text { surveys,result of staff } \\
\text { processsurvey,chart review }\end{array}$ & Team & $\begin{array}{l}\text { \%staff compliance } \\
\text { protocol; \%increase in } \\
\text { knowledge on surveys based } \\
\text { upon training ; \%training } \\
\text { effectiveness rating, } \% \\
\text { training revision require }, \% \text { re } \\
\text { training required }\end{array}$ & Data review & $\begin{array}{l}\text { Statistical } \\
\text { analysis; } \\
\text { Qualitative } \\
\text { Analysis }\end{array}$ & Pre- and Post-training \\
\hline $\begin{array}{l}\text { Is there a } \\
\text { decrease in } \\
\text { CAUTI }\end{array}$ & $\begin{array}{l}\text { Reduced CAUTI } \\
\text { in elderly with } \\
\text { Foley indwelling } \\
\text { catheters }\end{array}$ & Chart review & Team & $\begin{array}{c}\text { \# Catheterised patients } \\
\text { with CAUTI,\# Catheterised } \\
\text { patients without CAUTI }\end{array}$ & Data review & $\begin{array}{l}\text { Descriptive } \\
\text { statistics }\end{array}$ & $\begin{array}{l}\text { Two months following } \\
\text { pilot study }\end{array}$ \\
\hline
\end{tabular}

Table 3: Short -Term Evaluation plan.

\begin{tabular}{|c|c|c|c|c|c|c|}
\hline Evaluation Question & Indicators & $\begin{array}{c}\text { Source of } \\
\text { information }\end{array}$ & Individuals & Data Collected & Data Analysis & Time Frame for Reporting \\
\hline $\begin{array}{c}\text { How do our statistics on } \\
\text { CAUTI incidence compare } \\
\text { to NHSN CAUTI infection } \\
\text { rate }\end{array}$ & $\begin{array}{c}\text { Reduced CAUTI in elderly } \\
\text { with Foley indwelling } \\
\text { catheters }\end{array}$ & Chart review & Team & Chart review & $\begin{array}{l}\text { Data review; } \\
\text { descriptive } \\
\text { statistics }\end{array}$ & $\begin{array}{l}\text { Two months Post- } \\
\text { implementation }\end{array}$ \\
\hline $\begin{array}{l}\text { Was education and training } \\
\text { sufficient? }\end{array}$ & $\begin{array}{l}\text { Clinical practice and } \\
\text { processes followed } \\
\text { as affected by the } \\
\text { implementation }\end{array}$ & $\begin{array}{l}\text { Chart review, } \\
\text { education survey }\end{array}$ & Team & $\begin{array}{l}\text { Chart review; survey } \\
\text { results; in-office } \\
\text { process efficiency } \\
\text { observation }\end{array}$ & $\begin{array}{l}\text { Data review; } \\
\text { descriptive } \\
\text { statistics }\end{array}$ & $\begin{array}{l}\text { Two months Post- } \\
\text { implementation }\end{array}$ \\
\hline $\begin{array}{l}\text { How do the change results } \\
\text { compare to original change } \\
\text { goals? }\end{array}$ & Session with team & $\begin{array}{c}\text { Results from } \\
\text { previous evaluations }\end{array}$ & Team & $\begin{array}{c}\text { Results from previous } \\
\text { evaluations }\end{array}$ & Data review & $\begin{array}{l}\text { Three, six twelve, } \\
\text { and } 24 \text { months Post- } \\
\text { implementation }\end{array}$ \\
\hline $\begin{array}{c}\text { What new strengths, } \\
\text { weaknesses, opportunities, } \\
\text { and threats resulted from } \\
\text { the change? }\end{array}$ & Session with team & $\begin{array}{c}\text { Results from } \\
\text { previous evaluations }\end{array}$ & Team & $\begin{array}{c}\text { Results from previous } \\
\text { evaluations }\end{array}$ & Data review & $\begin{array}{l}\text { Three, six twelve, } \\
\text { and } 24 \text { months Post- } \\
\text { implementation }\end{array}$ \\
\hline $\begin{array}{l}\text { What lessons learned can } \\
\text { help achieve a smoother } \\
\text { implementation in }\end{array}$ & Session with team & $\begin{array}{c}\text { Results from } \\
\text { previous evaluations }\end{array}$ & Team & $\begin{array}{c}\text { Results from previous } \\
\text { evaluations }\end{array}$ & Data review & $\begin{array}{l}\text { Three, six twelve, } \\
\text { and } 24 \text { months Post- } \\
\text { implementation }\end{array}$ \\
\hline
\end{tabular}

Table 4: Long- Term Evaluation plan.

would automatically note the time, date, practitioner, and course of action taken. These fields would be required to remove the alert. Should the practitioner ignore the alert, it would then send an automatic alert to said practitioner's supervisor, and on up the chain of command. This would prevent many of the problems currently associated with practitioners ignoring physical reminders [8]. Phase 2 should also include an option for practitioners to proactively enter the virtual reminder system to update the patients' catheter status either directly, or when charting notes are entered, for key words such as 'catheter' to automatically populate appropriate fields and criteria into the reminder system.

\section{Discussion}

As has been highlighted throughout this project narrative, Foley catheters are in widespread use throughout the NHS, and are often considered a long-term medical [17]. However, Gotelli [17] suggest that there are many challenges to the delivery of quality patient care for this patient population, as proper catheter care, from placement through removal, are often fought with challenges. For example, inappropriate placement is frequently a cause of concern [17]. However, of greater concern in relation to incidence of CAUTI is the problem cause by catheters remaining in place beyond their intended use [17]. Successful process changes, ranging from education reminder systems to reminder systems [8] and the integration of a best practices protocol based upon recommended guidelines has been shown to decrease incidence of CAUTI from $24 \%$ to $17 \%$ [17].
The current implementation and evaluation plans presented herein were the result of a comprehensive approach to identifying challenges in healthcare that created the urgent need to reduce incidence of CAUTI for elderly patients with indwelling Foley catheters in the homecare setting. Based upon a successful outcome, this chapter will present a discussion highlighting the various implications of the current implementation plan to culminate in an effective approach to significantly reducing the number of CAUTI affecting our patients in accordance with the SMART goals identified. Although the ultimate goal is a reduction in incidence of CAUTI as a method consistent with continuous quality improvement in the delivery of healthcare, project implications reach beyond enhanced patient care, to encompass implications for the organisation, for clinical practice. Additionally, the project itself presented with a variety of strengths and weakness in both approach to the plan and to the implementation process; these will be discussed herein. Finally, recommendations for Phase 2 of the project will be presented.

\section{Implications of the project on the organization}

The current project brings with it many positive implications for GLTD. For example, it is projected there will be a $20 \%$ cost savings to GLTD based upon reduced patient care requirements associated with CAUTI as an additional burden over and above traditional Foley catheter provision of care. This also factors into the associated safety ranking of GLTD within NHS safety statistics regarding HAI and 
CAUTI in particular. Finally, the current project will place GLTD in the role of leader in CAUTI management and prevention protocols when final evaluations are received and analysed, and the final stage in the IHI Model [14] spreading the change is initiated.

\section{Implications of the project on the clinical practice}

As highlighted by Saint, it is critical to implement effective programmes that transcend the evidence versus practice barrier, and foster the integration of new evidence-based literature into the clinical setting. Therefore, it is believed the current reminder project achieves this critical juncture through the effective implementation of reminder stickers that have been demonstrated as successfully reducing the incidence of CAUTI in the clinical setting [8]. Additionally the use of educational programmes as part of the implementation effort, demonstrated as effective in reducing incidence of CAUTI on their own [8], when coupled with the reminder, should provide a significant reduction in incidence of CAUTI. This is particularly important for adding to the existing body of literature on incidence of CAUTI in the elderly in a homecare environment already known to be at a premium [12]. When faced with complications from infections of any sort, particularly when requiring intravenous antibiotic administration, it is difficult in the homecare setting to treat, due to poor venous access. Therefore, proper prevention of Foley complications such as CAUTI based upon the current reminder system will significantly improve the quality of patient care.

\section{Personal implications of the project}

There were a number of personal implications based upon the project, ranging from the conceptual phase through the development of evaluation plans. Whilst there were professional implications related to GLTD and my position as Deputy Chairperson, the personal implications were more far reaching, as they contributed to personal development goals as an effective leader, as a successful change agent, and as someone skilled at both comprehensive and strategic approach design and development. This project has the potential to serve as a springboard into the study of healthcare informatics, having created a desire to explore this area in greater depth based upon thoughts and criteria developed for Phase 2 as outlined above. Therefore, this project fostered the personal goal of a second master's degree in Healthcare Informatics.

\section{Summary and Concluding Remarks}

Whilst the use of medical devices is increasing, incidence of device-related HAI are increasing as well, with CAUTI cited as one of the most common negative consequences. Although HAI are commonly associated with inpatient hospitalisations, many patients are faced with the medical necessity of utilising indwelling catheters in the homecare setting, giving rise to a new population of patients experiencing device-related HAI, and in particular CAUTI. Therefore, to reach this population with an identified need within the patient care profiles of the GLTD organisation, the current project demonstrated a comprehensive approach to the implementation of a physical reminder system sticker protocol designed to reduce incidence of CAUTI and effectively manage patients with indwelling catheters.

Following the comprehensive discussions presented in prior chapters related to the evidence base supportive of the current implementation, and a detailed presentation of both the change and action plan, followed by short- and long-term evaluation plans, this chapter presented a robust assessment of the implications to the GLTD, to clinical practice and to this change agent. Further, this chapter assessed overall strengths and weakness of the implementation process followed by suggested recommendations, including a Phase 2 concept to add to the comprehensive nature of the current change and further the reduction of CAUTI incidence in elderly patients with indwelling Foley's catheters in the homecare setting.

\section{References}

1. Institute for Healthcare Improvement (2014) Catheter-Associated Urinary Tract Infection. Institute for Healthcare Improvement.

2. Jacobsen SM, Stickler DJ, Mobley HL (2008) Complicated catheterassociated urinary tract infection due to Escherichia coli and Proteus mirabilis. Clin Microbiol Rev 21: 26-59.

3. CDC (2015) Urinary Tract Infection (Catheter-Associated Urinary Tract Infection [CAUTI] and Non-Catheter-Associated Urinary Tract Infection [UTI]) and Other Urinary System Infection [USI]) events.

4. Gokula RR, Hickner JA, Smith MA (2004) Inappropriate use of urinary catheters in elderly patients at a Midwestern community teaching hospital. American journal of Infection Control 32: 196-199.

5. Fakih MG, Greene MT, Kennedy EH, Meddings JA, Krein SL, et al. (2012) Introducing a population-based outcome measure to evaluate the effect of interventions to reduce catheter-associated urinary tract infections. Am J Infect Cont 40: 359-364

6. Bruminhent J, Keegan M, Lakhani A, Roberts IM, Passalacqua J (2010) Effectiveness of a simple intervention for prevention of catheter-associated urinary tract infections in a community teaching hospital. Am J Infect Cont 38: 689-693.

7. Goetz AM, Kedzuf S, Wagener M, Muder RR (1999) Feedback to nursing staff as an intervention to reduce catheter- associated urinary tract infection. Am J Infect Cont 27: 402-404.

8. Meddings J, Rogers MAM, Krien SL, Fakih MG, Olmsted RN, et al. (2013) Reducing unnecessary urinary catheter use and other strategies to prevent catheter--associated urinary tract infection: An integrative review. BMJ Quality and Safety 1-13.

9. MacPhee M (2007) Strategies and tools for managing change. Journal of Nursing Administration 37: 405-405.

10.Gould CV, Umscheid CA, Agarwal, RK, Kuntz G, Peguees DA (2009) Guidelines for Prevention of Catheter- Associated Urinary Tract Infections 2009. Healthcare Infection Control Practices Advisory Committee.

11.Bernard MS, Hunter K F, Moore KN (2012) A review of strategies to decrease the duration of indwelling urethral catheters and potentially reduce the incidence of catheter-associated urinary tract infections. Urologic Nursing 32: 29-37

12.Getliffe K, Newton T (2006) Catheter-associated urinary tract infection in primary and community health care. Age and Ageing 35: 477-481.

13.Altun I, Karakoc A (2010) The impact of an interactive workshop on the management of urinary catheterization on nurses. Int $\mathrm{J}$ Urolog Nursing 4:125-132.

14.Langley GL, Nolan KM, Nolan TW, Norman CL, Provost LP (2009) The Improvement Guide: A Practical Approach to Enhancing Organizational Behavior. San Francisco: Jossey-Bass Publishers.

15. APIC (2008) Guide to the elimination of catheter-associated urinary tract infections. APIC

16.Donaldson SI, Gooler LE, Scriven M (2002) Strategies for managing evaluation anxiety: Toward a psychology of program evaluation. Am J Evalut 23: $261-273$.

17.Gotelli JM, Merryman P, Carr C, McElveen L, Epperson C, et al. (2008) A quality improvement project to reduce the complications associated with indwelling urinary catheters. Urologic Nursing 28: 465-467. 